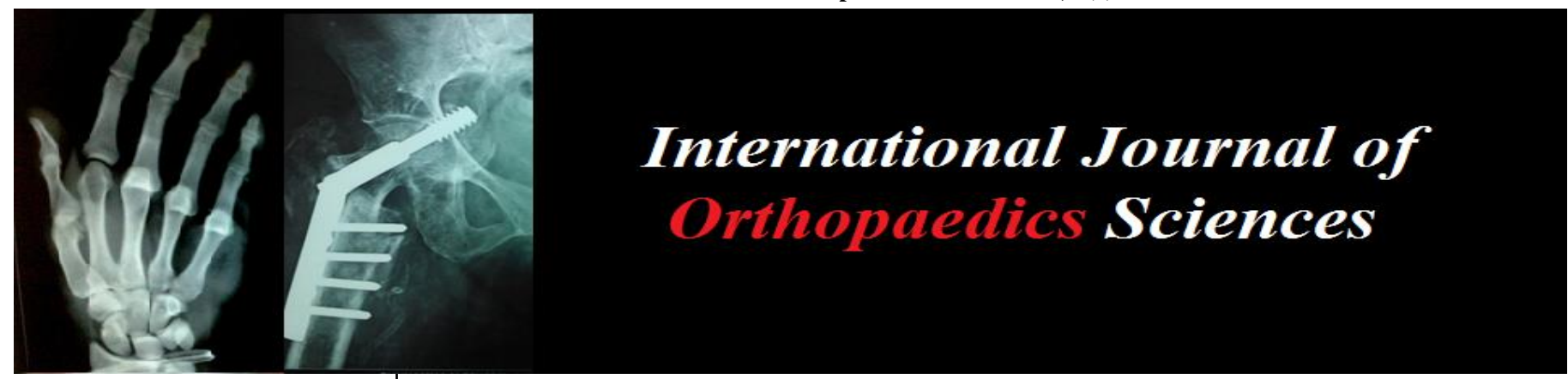

E-ISSN: 2395-1958

P-ISSN: 2706-6630

IJOS 2020; 6(1): 470-474

(C) 2020 IJOS

www.orthopaper.com

Received: 06-11-2019

Accepted: 10-12-2019

Dr. Bharath Narayanaswamy M.S. (ortho) Associate Professor, Department of Orthopaedic Surgery, Arupadai Veedu Medical College Hospital \& Research Institute, Pondicherry, India

Corresponding Author: Dr. Bharath Narayanaswamy M.S. (ortho) Associate Professor, Department of Orthopaedic Surgery, Arupadai Veedu Medical College Hospital \& Research Institute. Pondicherry, India

\section{Surgical site infections in orthopaedic surgeries a prospective study}

\section{Dr. Bharath Narayanaswamy}

DOI: https://doi.org/10.22271/ortho.2020.v6.i1i.1909

\section{Abstract}

Aim: To study the incidence of surgical site infections and the toll it takes on

Materials and Methods: Individuals above 18 years of age, underwent surgeries at Arupadai veedu Medical College, Pondicherry, between July 2017 - July 2019.

Sample Size: 100 Patients e third day, twelveth day, at the end of three months and six months.

Inclusion criteria

- Patients aged 18 years and above.

- Patients taken up for elective surgeries (major or minor procedures).

Exclusion criteria

- Immunocompromised patients.

- Patients on long term cortico-steroids and immunosuppressive treatment.

- Patients with open fractures.

Antibiotic selection: Third generation Cephalosporin i.e; Ceftriaxone and Ceftriaxone+Sulbactam. were used for all the patient.

Pre operative preparation: All patients received Injection Ceftriaxone $1.5 \mathrm{gm}$ intravenously the day of the surgery.

Post operative care: Injection Ceftriaxone was continued in the post operative period. The wound was inspected for any evidence of infection starting from the 3rd day and then 12th postoperative day. Patients were followed up till discharge. For the patient who satisfied any of the criteria for wound infection, wound swab was sent to the clinical microbiology laboratory for routine culture methods and repeat CRP and ESR was done.

Results: Of the 100 patients in this study, the overall incidence in the study is $4 \%$, which compares favorably with studies of Marston et al. who reported 5\% superficial and $0.25 \%$ deep infection in 413 replacements in ideal circumstances. Significant correlation was noted between antibiotic administration and timing of surgery similar to guidelines stipulated by Woods RK, Dellinger EP.

\section{Conclusion:}

1. This study did not show any statistically significant correlation between age, scrub time, spirit used with respect to incidence of infection.

2. The incidence of infection by gram +ve bacteria was higher than that of gram +ve bacteria.

3. Antimicrobial use is widespread and inconsistent with published guidelines.

4. Pathogens isolated are often resistant to commonly used antimicrobials.

5. The actual incidence of infection could be significantly higher than that showed by the study as the patients were only followed up at 3 months, after being discharged from hospital and not in between.

Keywords: surgical site infection, SSI, orthopaedic surgery

\section{Introduction}

In 1862, Louis Pasteur's ingenious experiments into the nature of putrefaction were officially endorsed by the Paris Academy of Science. The endorsement signaled an end to the long-held belief that the exposure of organic material to air brought about the "spontaneous generation" of microorganisms, and the concepts of "sepsis" and "asepsis" became firmly established. As noted by McDermott and Rogersl the greatest impact of the antibiotic revolution may be related, in the long run, to its essential role in supporting the advancements of modern surgery. 
Indeed, surgery as we know it today would be impossible in an environment in which infection was likely or, once established, untreatable.

Hippocrates (Greek physician and surgeon, 460-377 BC), known as the father of medicine, used vinegar to irrigate open wounds and wrapped dressings around wounds to prevent further injury. His teachings remained unchallenged for centuries.

Robert Koch (Professor of Hygiene and Microbiology, Berlin, 1843-1910) first recognized the cause of infective foci as secondary to microbial growth in his nineteenth century postulates. Joseph Lister demonstrated the incredible implications of antisepsis ${ }^{7}$ in his practice of Orthopaedic surgery. He recognized that antisepsis could prevent infection (Lister, 1867). Then he placed carbolic acid into open fractures to sterilize the wound and prevent sepsis and hence the need for amputation. In 1871, Lister began to use carbolic spray in the operating room to reduce contamination.

\section{Aims of the study}

To study the incidence of surgical site infections and the toll it takes on

\section{Orthopaedic surgeries by evaluating}

- The effectiveness of usage of preoperative and postoperative systemic antibiotics ${ }^{[2]}$.

- The role of sterile measures such as scrub suits, masks, sterile gloves, gowns, drapes and operation theatre environments, in reducing the surgical site infection ${ }^{[3]}$.

- To assess the efficacy of surgical asepsis (surgeons hand scrub, alcohol based agents, antibiotics and shaving) in Orthopaedic surgeries

\section{Materials and methods}

This is a prospective study which was conducted in the Department of Orthopaedics, Arupadai veedu Medical College, Pondicherry, between July 2017 to July 2019. A total of 100 patients underwent elective Orthopaedic surgeries were included in the study. The aim of the study was to study the incidence of postoperative wound infections and the toll it takes on Orthopaedic surgeries by evaluating the effectiveness of usage of preoperative and postoperative systemic antibiotics ${ }^{4}$, the role of sterile measures such as scrub suits, masks, sterile gloves, gowns, drapes and operation theatre environments, in reducing the surgical site infection and in assessing the efficacy of surgical asepsis (that is surgeons hand scrub, antibiotics used prior to surgery, shaving prior to surgery and use of antibiotics prior to surgery) in Orthopaedic surgeries.

\section{Inclusion criteria}

The inclusion criteria were patients aged 18 years and above and patients that were taken up for elective surgeries (major or minor procedures).

\section{Exclusion criteria}

The exclusion criteria were patients who were immunocompromised, patients on long term corticosteroids, immunosuppressive treatment and patients with open fractures needing external fixation devices.

\section{Patient Selection}

Individuals between 18-50 years of age, that underwent surgeries at Arupadai veedu Medical College, Pondicherry, between July 2017 - July 2019. and the data received was recorded in individual patient proformas obtained on admission and on out patient basis to Arupadai veedu Medical College, Pondicherry, between July 2017 - July 2019.

Patients were informed about the study in their vernacular language.

\section{Antibiotic selection}

Third generation Cephalosporin, i.e; Ceftriaxone and a combination of Ceftriaxone and Sulbactam were used for all the patients.

\section{Pre operative preparation}

All patients received Injection Ceftriaxone $1.5 \mathrm{gm}$ on the day of the surgery.

\section{Aseptic precautions in the operation theatre}

All routine aseptic precautions were taken like using autoclaved gowns, drapes, sterile gloves and instruments. Standard surgical scrub was done for 5 minutes before performing the operation.

\section{Operative}

The incision site was painted with $5 \%$ povidone iodine and spirit. The principles of surgery were followed in all cases such as minimum tissue handling and maintenance of adequate haemostasis. Drains were used whenever necessary. Skin closure was done with suture material or skin staples. Betadine or Neosporin ointment was used to cover the suture/staples followed by adhesive dressing.

\section{Post operative care}

Injection Ceftriaxone was continued in the postoperative period. The wound was inspected for any evidence of infection starting from the 3rd day and then 12th post operative day. Patients were followed up till discharge. For the patient who satisfied any of the criteria for wound infection, wound swab was sent to the clinical microbiology laboratory for routine culture methods. The incidence rate was calculated for each wound separately. Collected data was analyzed by ' $t$ '-test and Chi-Square test. About 100 adult patients who were taken up for elective procedures, at Arupadai veedu Medical College Hospital were evaluated and assessed preoperatively, intraoperatively and postoperatively for a period ranging 6-24 months.

\section{Results}

Total of 100 patients were enrolled for this study, out of which 4 patients were found to have infection at the operative site on postoperative day 3 . The overall incidence in this study was $4 \%$.

Table 1: Incidence of surgical site infection

\begin{tabular}{|c|c|c|}
\hline & No. of patients. & Percent. \\
\hline Absent. & 96 & 96 \\
\hline Present. & 4 & 4 \\
\hline Total. & 100 & 100 \\
\hline
\end{tabular}




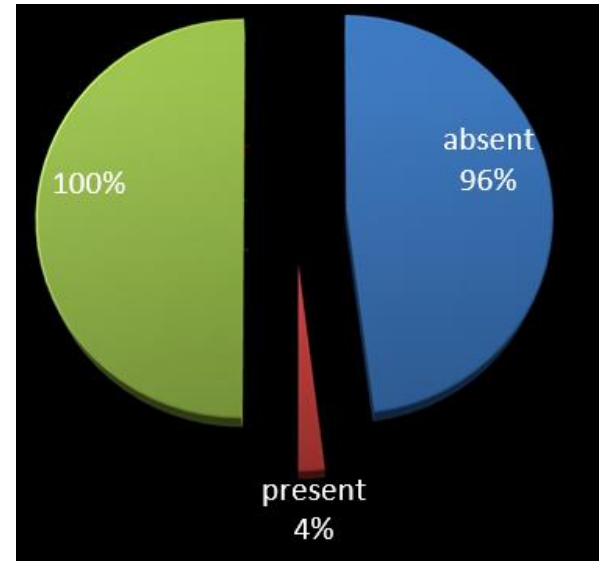

Fig 1: Incidence of surgical site infection.

Table 2: Incidence in relation to age group

\begin{tabular}{|c|c|c|c|c|}
\hline & \multicolumn{2}{|c|}{ Infection } & \multirow{2}{*}{ Total } \\
\hline & & Absent & Present & \\
\hline \multirow{7}{*}{ Age } & $\begin{array}{c}20 \text { yrs and } \\
\text { below }\end{array}$ & $\begin{array}{c}12 \\
100.0 \%\end{array}$ & $\begin{array}{c}0 \\
.0 \%\end{array}$ & $\begin{array}{c}12 \\
100.0 \%\end{array}$ \\
\hline & $21-30$ & $\begin{array}{c}18 \\
94.7 \%\end{array}$ & $\begin{array}{c}1 \\
5.3 \% \\
\end{array}$ & $\begin{array}{c}19 \\
100.0 \% \\
\end{array}$ \\
\hline & $31-40$ & $\begin{array}{c}13 \\
100.0 \%\end{array}$ & $\begin{array}{c}0 \\
.0 \%\end{array}$ & $\begin{array}{c}13 \\
100.0 \%\end{array}$ \\
\hline & $41-50$ & $\begin{array}{c}24 \\
96.0 \%\end{array}$ & $\begin{array}{c}1 \\
4.0 \%\end{array}$ & $\begin{array}{c}25 \\
100.0 \%\end{array}$ \\
\hline & $51-60$ & $\begin{array}{c}9 \\
100.0 \% \\
\end{array}$ & $\begin{array}{c}0 \\
.0 \% \\
\end{array}$ & $\begin{array}{c}9 \\
100.0 \% \\
\end{array}$ \\
\hline & $61-80$ & $\begin{array}{c}15 \\
88.2 \%\end{array}$ & $\begin{array}{c}2 \\
11.8 \%\end{array}$ & $\begin{array}{c}17 \\
100.0 \%\end{array}$ \\
\hline & Above 80 & $\begin{array}{c}5 \\
100.0 \%\end{array}$ & $\begin{array}{c}0 \\
.0 \%\end{array}$ & $\begin{array}{c}5 \\
100.0 \%\end{array}$ \\
\hline & Total & $\begin{array}{c}96 \\
96.0 \%\end{array}$ & $\begin{array}{c}4 \\
4.0 \%\end{array}$ & $\begin{array}{c}100 \\
100.0 \%\end{array}$ \\
\hline
\end{tabular}

Fishers exact test $\mathrm{p}$ value: $\mathbf{0 . 6 2 2}$, NS.

On analysis of incidence in relation to age for infection in this study, it was found that maximum incidence was in 41-50 age group (96\%), the next largest group being 21-30 yrs (94\%) and $61-80$ yrs $(88.2 \%)$ had least incidence

Table 3: Incidence in relation to hospital stay

\begin{tabular}{|c|c|c|c|c|}
\hline Infection & $\mathbf{N}$ & Mean & $\begin{array}{c}\text { Std. } \\
\text { Deviation } \\
\mathbf{t}\end{array}$ & $\mathbf{p}$ \\
\hline $\begin{array}{c}\text { Preop-stay Present } \\
\text { Absent }\end{array}$ & $\begin{array}{l}4.5000 \\
3.0625 \\
\end{array}$ & $\begin{array}{l}4.12311 \\
3.19807 \\
\end{array}$ & .872 & $\begin{array}{l}.385 \\
\text { NS } \\
\end{array}$ \\
\hline $\begin{array}{c}\text { Postop-stay } \\
\text { Present } \\
\text { Absent }\end{array}$ & $\begin{array}{c}7.7500 \\
10.6146\end{array}$ & $\begin{array}{l}4.92443 \\
3.71447\end{array}$ & 1.494 & $\begin{array}{c}.138 \\
\text { NS }\end{array}$ \\
\hline
\end{tabular}

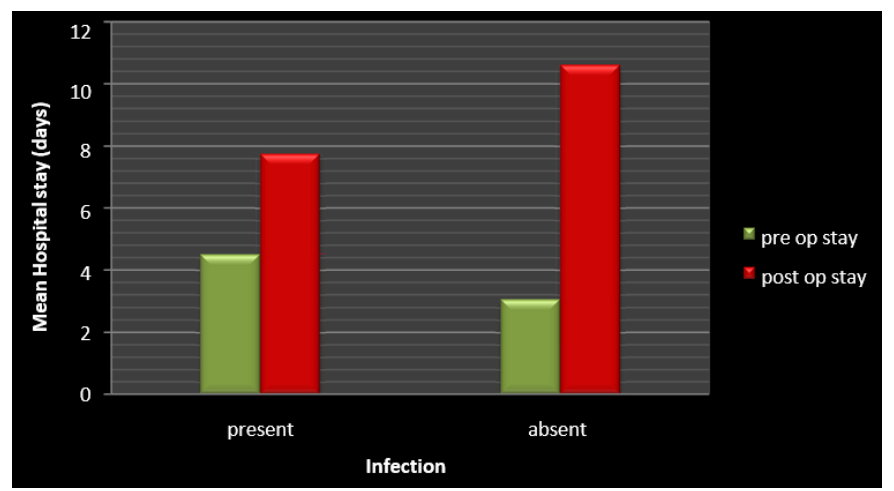

Fig 2: Incidence in relation to hospital stay
The mean preoperative stay in infected cases was 4.50 days, when compared to 3.06 days in non infected cases which is statistically not significant.

The mean post operative stay in infected cases was 7.75 days, when compared to 10.16 days in non infected cases which is statistically not significant.

Table 4: Incidence in relation to duration of surgery

\begin{tabular}{|c|c|c|c|c|}
\hline & \multicolumn{2}{|c|}{ Infection } & \multirow{2}{*}{ Total } \\
\hline & & Absent & Present & \\
\hline \multirow{3}{*}{$\begin{array}{l}\text { Duration } \\
\text { of surgery }\end{array}$} & below $1 \mathrm{hr}$ & $\begin{array}{c}11 \\
100.0 \%\end{array}$ & $\begin{array}{c}0 \\
.0 \%\end{array}$ & $\begin{array}{c}11 \\
100.0 \%\end{array}$ \\
\hline & $1-2 \mathrm{hrs}$ & $\begin{array}{c}57 \\
100.0 \%\end{array}$ & $\begin{array}{c}0 \\
.0 \%\end{array}$ & $\begin{array}{c}57 \\
100.0 \% \\
\end{array}$ \\
\hline & Above $2 \mathrm{hrs}$ & $\begin{array}{c}28 \\
87.5 \%\end{array}$ & $\begin{array}{c}4 \\
12.5 \%\end{array}$ & $\begin{array}{c}32 \\
100.0 \%\end{array}$ \\
\hline \multicolumn{2}{|c|}{ Total } & $\begin{array}{c}96 \\
96.0 \%\end{array}$ & $\begin{array}{c}4 \\
4.0 \% \\
\end{array}$ & $\begin{array}{c}100 \\
100.0 \%\end{array}$ \\
\hline
\end{tabular}

Fishers exact test $\mathrm{p}=0.0208$, significant

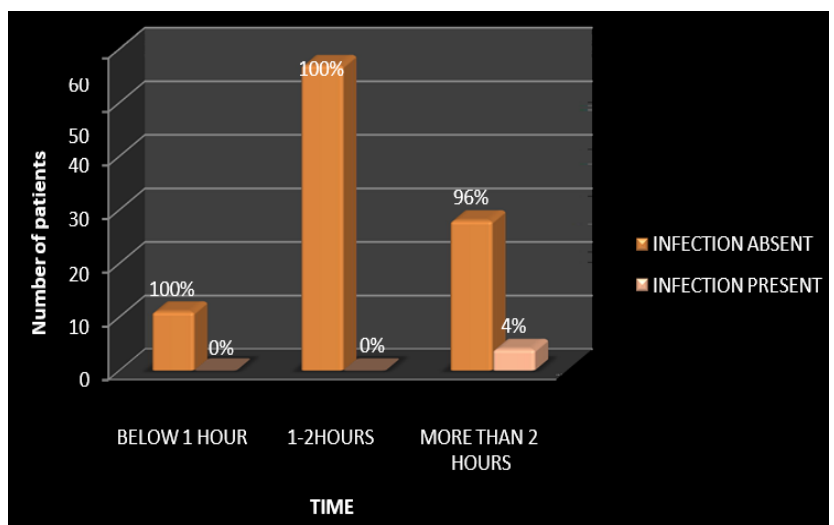

Fig 3: Incidence in relation to duration of surgery

Correlation between duration of surgery ${ }^{[5]}$ and incidence of infection in major surgeries was found to be statistically significant with $\mathrm{p}$ value 0.0208 .

Table 5: Incidence in relation to time of antibiotic administration and start of surgery

\begin{tabular}{|c|c|c|c|c|c|}
\hline & $\begin{array}{c}\text { X2 value and } \\
\text { p value }\end{array}$ & \multicolumn{3}{|c|}{$\begin{array}{c}\text { Fishers exact } \\
\text { test p value }\end{array}$} \\
\hline Age * Infection &. &. &. & .622 & $\mathrm{NS}$ \\
\hline Sex * Infection & & 0.239 & $\mathrm{NS}$ &. &. \\
\hline Surgery(major/mi & & & & .142 & $\mathrm{NS}$ \\
\hline Sprirt used * Infection & .495 & .482 & $\mathrm{NS}$ & & \\
\hline $\begin{array}{c}\text { No. of individuals in theatre * } \\
\text { Infection }\end{array}$ & .150 & .698 & $\mathrm{NS}$ & & \\
\hline Type * Infection &. & & & .279 & $\mathrm{NS}$ \\
\hline Antibiotic * Infection & .001 & .975 & $\mathrm{NS}$ & & \\
\hline $\begin{array}{c}\text { Duration between antibiotic adm and } \\
\text { surgery * Infection }\end{array}$ & .219 & .0640 & $\mathrm{~S}$ & & \\
\hline
\end{tabular}

Fishers exact test $\mathrm{p}=0.0640$, significant.

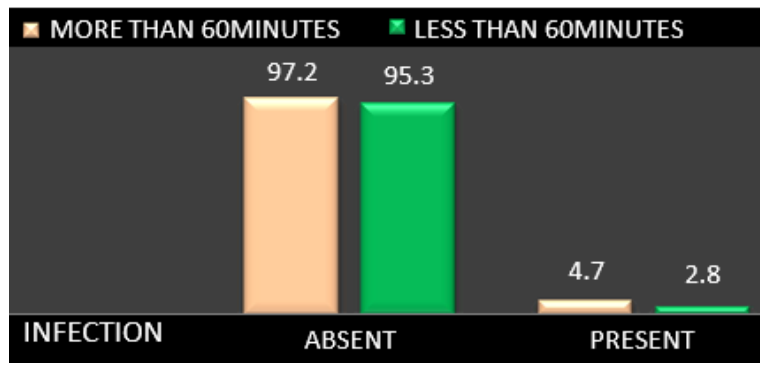

Fig 4: Incidence in relation to time of antibiotic administration and start of surgery 
Of the 4 patients with infection, the earliest occurrence was on day 3 with three patients and one developed infection on day 12 .

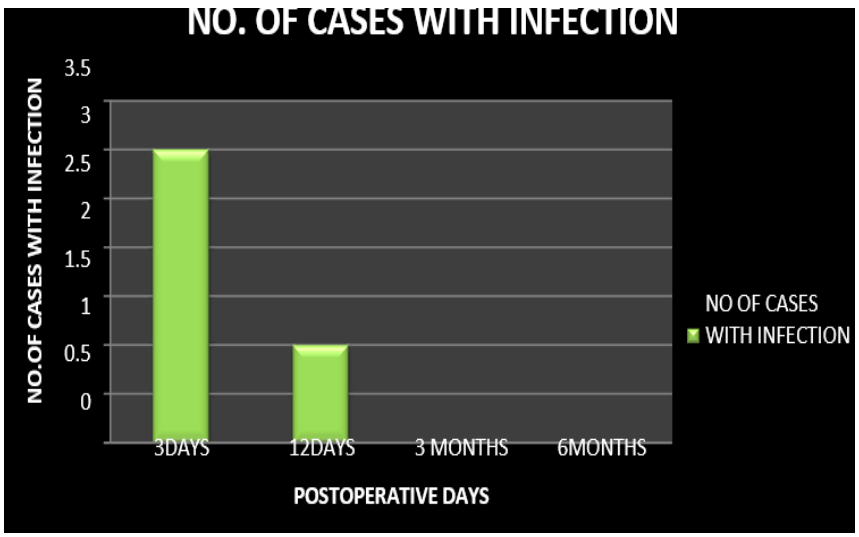

Fig 5: Incidence in relation to time of occurrence of infection

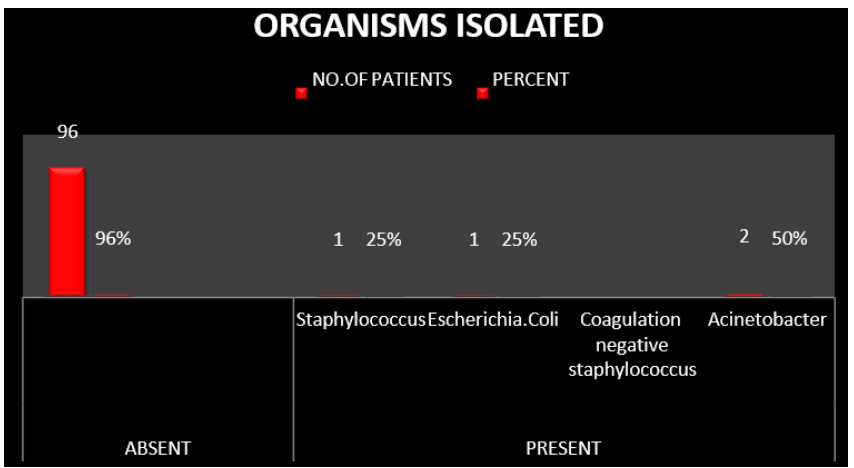

Fig 6: Incidence of infection in relation to organism isolated

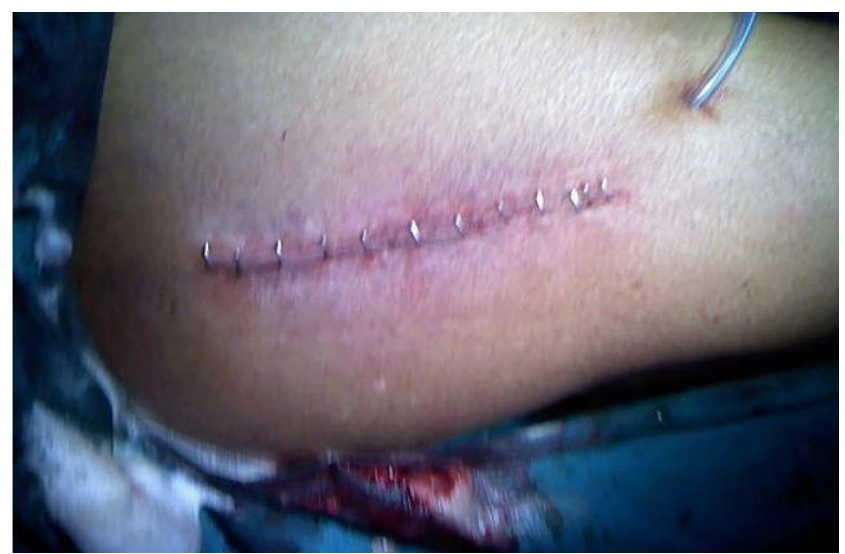

Fig 7: Operated site showing signs of infection on day 3 following fixation of fracture neck of femur

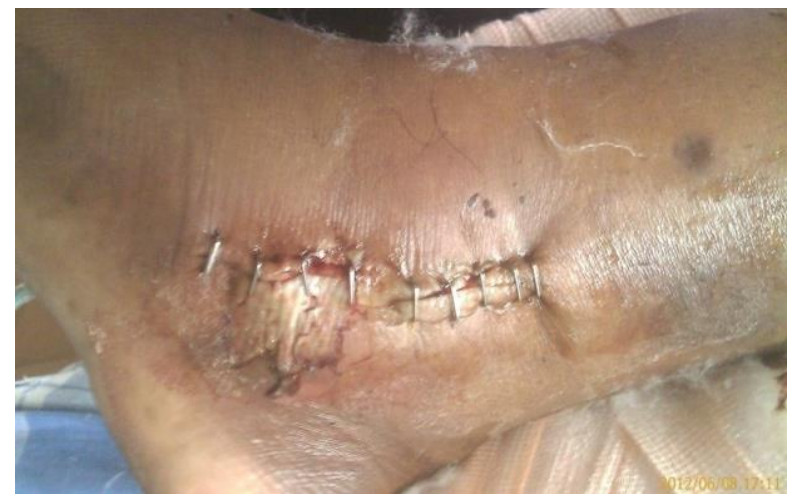

Fig 8: Operated site showing signs of infection on day 3 following bimalleolar fixation

\section{Discussion}

Of the 100 patients in this study, the overall incidence of surgical site infection in the study is $4 \%$, which compares favorably with studies of Marston et al. ${ }^{[8]}$ who reported $5 \%$ superficial and $0.25 \%$ deep infection in 413 replacements in ideal circumstances. The rate of postoperative wound infection without prophylactic antibiotic is high as compared to the use of prophylactic antibiotic8. Recent international studies show further decline in the postoperative infection rate with prophylactic antibiotics which is $0.23 \%, 1.06 \%, 1.09 \%$ and $1.34 \%{ }^{[9]}$. In my study the advanced age (41-50 age group $(96 \%)$, prolonged surgery time were responsible for infections as reported in other studies ${ }^{[9]}$.

In terms of the incidence of infection in relation to sex, there was marginal though statistically not significant higher incidence in females but no obvious or specific reason could be found to explain this. There was no correlation in terms of scrub time, chorhexidine used, spirit used and use of scrub brush. There was no significant correlation observed between the incidence of infection and type of anesthesia used and thus not considered to be a major factor. There was no significant relationship noted between the incidence of infection and the length of hospital stay.

There was significant correlation noted between antibiotic administration and timing of surgery similar to guidelines stipulated by Woods RK, Dellinger EP et al. ${ }^{[11]}$. Correlation between duration of surgery and antibiotic administration was found to be statistically significant with $\mathrm{p}$ value of 0.0208 which coincides with another study that stated that rate of infection was directly proportional to the length of the procedure where cases lasting one hour or less had a wound infection rate of $1.3 \%$ while that lasting for 2 hours or more it was $4 \%$. This is comparable to my study, i.e; 4 cases (4\%) got infected when procedures lasted more than 2 hours. [12] Literature shows that the timing of administration is critically important because the concentration of the antibiotic should be at therapeutic levels at the time of incision during surgical procedure, and ideally, for few hours post operatively (CDC1996). Study of the bacteriological profile shows most of the cases had single organism infection, the commonest organism isolated being Acinetobacter followed by Escherichia coli and Staphylococcus which is similar to organism profiles described in other studies. The earliest occurrence of infection was on the third postoperative day. Correlation between duration of surgery and time of antibiotic administration in relation to incidence of infection was found to be statistically significant, $4 \%$ infection present when there was a delay of more than 60 minutes. Literature shows that the risk of infection increases if there is a delay between starting of surgery and antibiotic administration ${ }^{[10]}$.

Most of the wound infections fell in Class II of the classification of surgical site infections which was statistically not significant.

\section{Conclusion}

Based on my prospective study of antibiotic prophylaxis, prophylactic regimens should be recommended for a wide variety of surgical procedures. There is marked variations in the spectrum of infecting pathogens and in the degree of antimicrobial resistance which exist among various hospitals. Moreover, variations in infecting pathogens and resistance patterns can and do occur over time within a given institution. Physicians and individual health care institutions must tailor routine prophylactic regimens ${ }^{6}$ based on carefully collected epidemiologic data regarding surgical wound infection. 
Equally important, many surgical procedures are far from routine, and numerous variations in perioperative circumstances will dictate deviations from established prophylactic regimens. Early re-explorations for postoperative bleeding, a history of penicillin or cephalosporin allergy, trauma and other emergency surgery and existing preoperative infections of non wound sites are important variables that may influence the choice and duration of perioperative prophylaxis. Studies are not available that can provide guidelines for such situations. A continuous assessment of failures of prophylaxis and a willingness to alter antiseptic and perioperative data are essential aspects of surgical wound prevention and antimicrobial prophylaxis.

\section{References}

1. McDermott W, Rogers DE. Social ramifications of control of microbial disease. Johns Hopkins Med J. 1982; 151:301-12.

2. Ketcham AS, Lieberman JE, West JT. Antibiotic prophylaxis in cancer surgery and its value in Staphylococcal carrier patients. Surg Gynecol Obstet. 1963; 117:1-6.

3. Howe CW, Marston AT. A study on sources of postoperative Staphylococcal infection. Surg Gynecol Obstet. 1962; 115:266-75.

4. Finland M. antibacterial agents: uses and abuses in treatment and prophylaxis. Rhode Island Med J. 1960; 43:499-520.

5. Kirkland KB, Briggs JP, Trivette SL. The impact of surgical site infections in the 1990's: attributable mortality, excess length of hospitalization and extra costs. Infect Control Hops Epidemiol. 1999; 20(11):725-730.

6. Krizek TJ, Robson MC. Evolution of quantitative bacteriology in wound management. Am J Surg. 1975: 130(5):579-584.

7. Elek SD, Coneh PE. The virulence of Staphylococcus pyogenes for man. A study of the problems of wound infection. Br J Exp Pathol. 1958; 38:573-86.

8. Martson RA, Cobb AG, Bantley G. Stammor compare with Charnley total hip replacement. J Bone J surg. 1996; 78:178-184.

9. Williams DN, Gustilo RB. The use of preventive antibiotic in Orthopaedic surgery. Clin Orthop Relat Res 1984; 190:83-8.

10. Weick JA, Jackson JK, O-Brien TJ, Lurate RB, Russell JM, Dorchak JD. Efficacy of prophylactic antibiotic in arthroscopic surgery. Orthopaedic. 1997; 20:133-4.

11. Woods RK, Dellinger EP. Current guidelines for antibiotic prophylaxis of surgical wounds. Am Fam Physician. 1998; 57(11):2731-2740.

12. Sawyer RG, Pruett TL. Wound infections. Surg Clin North Am. 1994; 74:519-36.

13. Olson M, O’Çonnor M, Schwartz ML. Surgical wound infections: a five year prospective study of 20, 193 wounds at the Minneapolis VA Medical Center. Ann Surg. 1984; 199:253-259. 